\title{
Copolimerização Micelar de Poli(Acrilamida-g-0́xido de Propileno): Avaliação Reológica e Caracterização de suas Soluções
}

\author{
Bianca L. Sadicoff, Edimir M. Brandão e Elizabete F. Lucas \\ Instituto de Macromoléculas Profa. Eloisa Mano, UFRJ
}

Marcia C. V. Amorim Instituto de Química, UERJ

Resumo: Copolímeros graftizados de poliacrilamida e poli(óxido de propileno) (PPO) foram sintetizados via técnica de polimerização micelar. Foram investigadas as mudanças de viscosidade das suas soluções frente à variação do teor de monômero hidrófobo incorporado ao copolímero, adição de sal e de tensoativo. O maior teor de grupos hidrófobos resultou em aumento da viscosidade aparente das soluções poliméricas. A adição de sal provocou maior interação entre os grupos hidrófobos verificada pela desestabilização do sistema polimérico. A adição de tensoativos gerou decréscimo das viscosidades reduzidas das soluções poliméricas. Os copolímeros obtidos foram caracterizados, qualitativamente, por espectrometria de absorção na região do infravermelho (FTIR).

Palavras-chave: Poliacrilamida, poli(óxido de propileno), copolimerização micelar, reologia.

\section{Micellar Copolymerization of Poly(acrylamide-g-propylene oxide): Rheologic Evaluation and Solution Characterization}

\begin{abstract}
Graft copolymers of polyacrylamide and poly(propylene oxide) (PPO) were synthesized by a micellar copolymerization technique. The rheological properties of the copolymers solutions were evaluated and compared with literature data for solutions of the same copolymers, synthesized by solution polymerization. The effect of hydrophobe content, salt addition and surfactant addition on the rheological properties were also investigated. Increasing hydrophobe content resulted in higher solution viscosities in the semi-dilute regime. Upon addition of salts, the hydrophobic groups associated to minimize their exposure to water. In the semi-dilute region, higher contents of surfactant added resulted in lower reduced viscosities of the polymer solutions. The copolymers were qualitatively characterized by infra-red spectrometry (IR).
\end{abstract}

Keywords: Polyacrylamide, poly(propylene oxide), micellar copolymerization, rheology.

\section{Introdução}

Nos últimos anos, vários estudos têm sido realizados no sentido de controlar e modificar a viscosidade de sistemas aquosos por meio da utilização de polímeros. O controle da viscosidade pode ser conseguido por meio da dissolução de polímeros de alto peso molecular $\left(\mathrm{M}_{\mathrm{w}} \approx 10^{7}\right)$ ou polieletrólitos ${ }^{[1]}$. Os polímeros à base de poliacrilamida estão classificados entre os modificadores de reologia mais potentes porque, entre outras razões, podem apresentar pesos moleculares ultra altos $\left(\mathrm{M}_{\mathrm{w}} \approx 10^{6}-10^{7}\right)^{[2]}$. No entanto, esses materiais são susceptíveis à degradação por cisalhamento sob altas taxas, levando à perda de viscosidade quando do retorno da solução às condições de cisalhamento tendendo a zero. Uma alternativa para evitar a degradação irreversível por cisalhamento é a utilização de polímeros de mais baixo peso molecular

Autor para correspondência: Elizabete F. Lucas, Instituto de Macromoléculas Prof. Eloisa Mano/UFRJ, Centro de Tecnologia, C. P.: 68525, CEP:21945-970, Rio de Janeiro, RJ.E-mail: elucas@ima.ufrj.br 
contendo pequenas quantidades de segmentos hidrófobos (1-5\%mol), que promovem espessamento equivalente ${ }^{[1,3]}$.

Os polímeros hidrossolúveis modificados hidrofobicamente, como são denominados, podem ser classificados como copolímeros anfifílicos por apresentarem na mesma molécula segmentos hidrófilos e hidrófobos ${ }^{[4-6]}$. Esses polímeros têm representado um importante papel como agentes espessantes em áreas de recuperação de petróleo ${ }^{[3,7]}$, tratamento de água ${ }^{[8]}$ e ingredientes farmacêuticos ${ }^{[4,9]}$. Esses materiais exibem um comportamento incomum em soluções aquosas $^{[10,11]}$ e propriedades reológicas acentuadamente diferentes das apresentadas pelos seus similares nãomodificados, ou seja, polímeros que não apresentam segmentos laterais hidrófobos. ${ }^{[11,12]}$ Particularmente, o uso de copolímeros de poliacrilamida com diferentes grupos funcionais provou ser de grande interesse ${ }^{[3]}$, devido ao seu baixo custo.

As técnicas convencionais de polimerização não têm se mostrado eficientes na síntese de copolímeros anfifílicos, uma vez que o meio reacional é constituído de monômeros hidrófilos e hidrófobos. A técnica de polimerização micelar tem sido estudada por pesquisadores em todo o mundo desde o início da década de 80 . Porém, no Brasil, essa técnica ainda é pouco conhecida. Portanto, a copolimerização apresenta vantagens na sua utilização e entre elas está a possibilidade de se copolimerizar monômeros solúveis e insolúveis no meio, por meio da adição de um tensoativo externo, gerando produtos homogêneos e livres de partículas ${ }^{[5]}$, e ainda, a obtenção de copolímeros com mais alto teor de incorporação de monômeros hidrófobos e altos pesos moleculares. Ao contrário das polimerizações em emulsão ou microemulsão, a técnica de polimerização micelar não necessita de hidrocarboneto ou óleo (para dissolver o monômero hidrófobo) nem de um cosurfatante e o produto de reação é totalmente livre de partículas de monômero hidrófobo. Na polimerização micelar faz-se uso apenas de um tensoativo capaz de solubilizar o monômero hidrófobo para formar uma mistura clara e homogênea. $\mathrm{O}$ tensoativo mais freqüentemente usado é o dodecilsulfato de sódio (SDS). Após dissolver o tensoativo na água, formam-se micelas, no interior das quais será totalmente realizada a solubilização do monômero hidrófoboo ${ }^{[5,7]}$.

A identificação do mecanismo de polimerização micelar tem sido dificultada por várias limitações. Uma delas decorre da dificuldade de se definir a forma de distribuição dos grupos hidrófobos no polímero, ou seja, a maneira pela qual os grupos hidrófobos incorporam-se na estrutura do polímero. Uma sugestão baseia-se na existência de uma estrutura de segmentos do tipo "microbloco", ou seja, os monômeros hidrófobos são polimerizados na forma de blocos e tendem a se agregar no interior de domínios micelares longe da fase aquosa, conforme esquematizado na Figura 1. E devido à alta densidade dos monômeros hidrófobos na micela, estes estão distribuídos aleatoriamente como blocos no esqueleto do polímero ${ }^{[13]}$.

O estudo do comportamento reológico de fluidos baseia-se, normalmente, na avaliação das alterações da viscosidade da solução polimérica frente a fatores como adição de sais, mudança de temperatura, mudança do grau de incorporação do grupo hidrófobo, mudança do peso molecular do polímero e variação da concentração de tensoativo adicionada à soluçãoo ${ }^{[7,14]}$.

O comportamento reológico da solução polimérica como função dos fatores anteriormente mencionados é muito importante para aplicação dos copolímeros na área de recuperação de petróleo. Os polímeros hidrossolúveis modificados hidrofobicamente, quando usados como agentes espessantes nessa área de aplicação, estão sujeitos a: presença de sais, que podem ser encontrados na água de formações subterrâneas; altas temperaturas, como as obtidas em aplicações nas quais o meio aquoso é bombeado a profundidades que variam de aproximadamente 1600 a $6600 \mathrm{~m}$; e altos cisalhamentos, como os encontrados no bombeamento dos fluidos ${ }^{[14]}$.

Os copolímeros de acrilamida modificados hidrofobicamente exibem viscosidade aumentada a partir de uma determinada concentração, denominada concentração crítica, na qual verifica-se a transição do

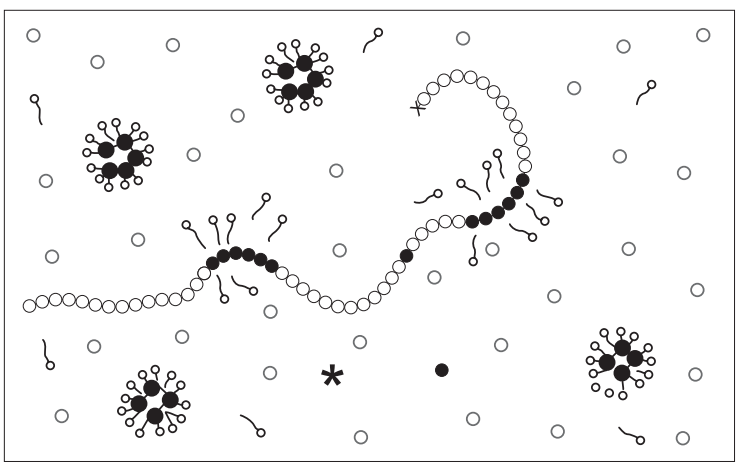

Figura 1. Representação esquemática do meio reacional na copolimerização micelar, sendo: $(\mathrm{O})$ monômero hidrossolúvel; $(\bullet)$ monômero hidrófobo; ( $\mathrm{O}-)$ tensoativo 
regime de concentração diluído para o semi-diluído $^{[15]}$. Em virtude da dependência da viscosidade com relação à concentração polimérica do meio e do intuito de utilizar os copolímeros como agentes viscosificantes, faz-se necessário um estudo de viscosidade a diferentes concentrações a fim de estabelecer o regime de concentração no qual foram avaliadas as propriedades reológicas dos copolímeros.

Para a realização da avaliação reológica de fluidos à base de poliacrilamida modificada hidrofobicamente, foram sintetizados copolímeros graftizados de poliacrilamida e poli(óxido de propileno) (PPO), de forma a obter um copolímero anfifílico e com comportamento reológico típico destes materiais. Os copolímeros foram sintetizados utilizando a técnica de copolimerização micelar e suas propriedades reológicas em solução foram comparadas às obtidas pelos mesmos copolímeros, anteriormente ${ }^{[16]}$ sintetizados via técnica em solução. Assim, tornou-se possível comparar o comportamento reológico de copolímeros de mais baixo peso molecular e mais facilmente caracterizáveis, obtidos via técnica de polimerização em solução, com aqueles obtidos via polimerização micelar.

O poli(óxido de propileno) ainda não é utilizado, como grupo hidrófobo, com a finalidade de gerar fluidos para recuperação de petróleo. Na verdade, as cadeias hidrocarbônicas (com 13 ou 17 átomos de carbono) são usadas para este fim, mas produzem soluções reacionais altamente viscosas e de difícil manuseio. $\mathrm{O}$ objetivo de estudar o PPO foi de avaliar os resultados que seriam obtidos, com um segmento menos hidrófobo do que cadeias hidrocarbônicas, em termos de viabilidade de manipulação da solução polimérica obtida no reator e em termos de propriedades reológicas dos fluidos a serem aplicados em recuperação de petróleo.

\section{Experimental}

\section{Síntese dos macromonômeros}

O procedimento descrito a seguir é baseado na literatura ${ }^{[16]}$ e refere-se à obtenção dos macromonômeros de metacrilato de poli(óxido de propileno), nos quais variou-se o peso molecular do PPO utilizado, 400 e 1000.

Inicialmente, foi realizada a secagem do PPO por meio de destilação azeotrópica com tolueno. Em seguida, $1 \mathrm{~mol}$ de PPO foi reagido com $0,5 \mathrm{~mol}$ de cloreto de metacriloíla (previamente sintetizado) ${ }^{[17]}$, em presença de piridina, sob agitação magnética, por uma hora, à temperatura ambiente. O produto obtido foi mantido em repouso por 24 horas e filtrado sob corrente de nitrogênio, a fim de se separar o cloridrato de piridina precipitado no balão durante o repouso. O macromonômero foi recuperado, por evaporação do tolueno, e estocado sob refrigeração.

\section{Síntese dos copolímeros}

A poliacrilamida bem como os copolímeros foram sintetizados utilizando-se o método de polimerização micelar adotado por Turner et $a l^{[12]}$. Primeiramente, o tensoativo, dodecil sulfato de sódio (SDS), foi dissolvido em água destilada sob agitação magnética. Em seguida, ainda sob agitação, os monômeros foram adicionados e o pH da solução medido. A mistura obtida foi vertida para um frasco de vidro e, em seguida, realizou-se purga com nitrogênio. Por fim, o persulfato de potássio (iniciador) foi adicionado e, rapidamente, o frasco de vidro foi vedado com tampa de alumínio, utilizando pressão. O frasco foi colocado em um banho termostatizado, dotado de suporte giratório, e mantido sob agitação constante por um período pré-determinado. Foram realizadas duas bateladas, uma por 10 e outra por 24 horas, na temperatura de $50^{\circ} \mathrm{C}$. Após a reação, parte da solução polimérica foi purificada e submetida à caracterização e avaliação reológica. As purificações dos copolímeros foram realizadas por meio de sucessivas dissoluções em água e precipitações do copolímero sobre metanol, seguidas de secagem a vácuo.

A Tabela 1 resume as quantidades de reagentes utilizados na síntese dos copolímeros e dos homopolímeros

Tabela 1. Condições reacionais das bateladas de polimerização micelar e quantidades adicionadas na alimentação.

\begin{tabular}{ccccc}
\hline Amostra & $\begin{array}{c}\text { Identificação } \\
\text { da amostra e } \\
\text { peso molecular } \\
\text { do PPO }\end{array}$ & $\begin{array}{c}\text { \% de } \\
\text { monômero } \\
\text { hidrófobo } \\
\text { (em massa) }\end{array}$ & $\begin{array}{c}\text { \% de } \\
\text { monômero } \\
\text { hidrófobo } \\
\text { (em mol) }\end{array}$ & $\begin{array}{c}\text { Tempo de } \\
\text { reação } \\
\text { (h) }\end{array}$ \\
\hline 1 & AM/PPO 400 & 0,7078 & 0,1264 & 10 \\
2 & AM/PPO 1000 & 0,3645 & 0,0260 & 10 \\
3 & AM/PPO 1000 & 0,6943 & 0,0496 & 10 \\
4 & AM & - & - & 10 \\
5 & AM/PPO 400 & 0,3526 & 0,0628 & 24 \\
6 & AM/PPO 400 & 0,6724 & 0,1200 & 24 \\
AM-1 & AM & - & - & 24 \\
AM-2 & AM & - & - & 24 \\
AM-3 & AM & - & - & 24 \\
\hline
\end{tabular}

Polímeros: Ciência e Tecnologia, vol. 11, no 2, p. 41-50, 2001 
de acrilamida via técnica de polimerização micelar, bem como as condições reacionais.

\section{Medidas reológicas}

\section{Medidas de viscosidade}

Todas as soluções obtidas das polimerizações micelares foram analisadas, na forma em que foram retiradas dos frascos reacionais, (denominadas soluções originais da polimerização - SOP). As análises de viscosidade (viscosidade aparente versus taxa de cisalhamento) foram realizadas no reômetro Contraves Low Shear LS-40 na temperatura de $30^{\circ} \mathrm{C}$.

As análises de viscosidade intrínseca foram realizadas apenas para as amostras 5 e 6 . Uma solução aquosa contendo $3 \%$ de SDS foi usada como solvente de diluição.

\section{Efeito da adição de tensoativos}

Para verificar o comportamento reológico das soluções poliméricas em função da concentração de tensoativo presente no meio, foram preparadas duas séries de diluições da solução de polímero purificado, utilizando como solvente duas soluções de SDS, uma a $3 \% \mathrm{p} / \mathrm{v}$ e outra a $1 \% \mathrm{p} / \mathrm{v}$.

Foram determinadas as viscosidades reduzidas dessas soluções a partir dos valores obtidos de tensão versus taxa de cisalhamento fornecidos pelo reômetro Low Shear LS-40, em cada concentração conhecida e a uma mesma temperatura, de $30^{\circ} \mathrm{C}$.

\section{Efeito da adição de sais}

Para se estudar a influência da presença de sal, foram utilizadas as soluções originais de polimerização das amostras 5 e 6, uma solução aquosa contendo $3 \%$ de SDS e água destilada e deionizada. Nesse estudo, pequenas quantidades conhecidas de sal ( $\mathrm{NaCl}$ puro) foram adicionadas a $10 \mathrm{~mL}$ da solução analisada, até a observação do ponto de saturação, ou seja, foi observada a quantidade máxima de sal que a solução suportava. A partir desta quantidade, observou-se a turbidez da solução. As massas de sal (em gramas), nas quais observava-se turbidez das soluções, foram convertidas para valores percentuais em peso de sal por volume de solução $(\mathrm{p} / \mathrm{v})$.

\section{Caracterização dos macromonômeros copolímeros}

A obtenção dos macromonômeros foi confirmada por meio de espectrometria de absorção na região do infravermelho (FTIR). As estruturas dos copolímeros e do homopolímero foram investigadas por meio de
FTIR, análise elementar e ressonância magnética nuclear de hidrogênio ( $\left.{ }^{1} \mathrm{H}-\mathrm{NMR}\right)$.

Os espectros de infravermelho foram obtidos a partir de filme vazado sobre célula de $\mathrm{AgBr}$, na região de 400 a $4000 \mathrm{~cm}^{-1}$, em espectrofotômetro de absorção na região do Infravermelho com Transformada de Fourier (FTIR) - Perkin Elmer, modelo 1720.

As fórmulas mínimas das amostras de copolímeros e de poliacrilamida foram investigadas a partir das suas composições percentuais de carbono, hidrogênio e nitrogênio em analisador elementar C-H-N Perkin Elmer 2400, sob temperatura de combustão de $925^{\circ} \mathrm{C}$ e temperatura de redução de $640^{\circ} \mathrm{C}$.

Os espectros de ressonância magnética nuclear de ${ }^{1} \mathrm{H}$ foram obtidos a partir de soluções da amostra, em tubo de $5 \mathrm{~mm}$, em espectrômetro VARIAN Gemini-300, na freqüência de 300,075 MHz e utilizando-se $\mathrm{D}_{2} \mathrm{O}$ como solvente.

\section{Resultados e Discussão}

Os macromonômeros obtidos, para serem utilizados na síntese do copolímero, foram caracterizados por FTIR. As Figuras 2a e $2 b$ apresentam os espectros do PPO (de peso molecular 400) e do metacrilato de poli(óxido de propileno), respectivamente. Uma banda a 1718, relativa à deformação axial da carbonila de éster, presente somente no espectro do macromonômero, confirma sua obtenção.

Assim como em alguns trabalhos publicados anteriormente ${ }^{[18]}$, a pequena concentração de grupos hidrófobos presentes nos copolímeros, sintetizados via técnica de polimerização micelar, dificultou a caracterização por meio de métodos tradicionais como NMR ou análise elementar, em termos quantitativos. Os valores teóricos de composição de monômero hidrófobo no copolímero encontram-se abaixo do limite de sensibilidade das técnicas utilizadas para quantificar composição e nenhum resultado confiável foi obtido, isto é, os teores de monômero hidrófobo nos copolímeros são, realmente, muito baixos. No entanto, a partir dos espectros de infravermelho da poliacrilamida e da amostra 6 (Figura 3), observa-se que o copolímero apresentou bandas características dos grupamentos funcionais de amida e de éter, respectivamente, aos segmentos hidrófilo e hidrófobo. O grupamento funcional éter está supostamente presente devido à modificação observada no espectro (b) em relação ao espectro (a) na faixa entre 1100 e $1300 \mathrm{~cm}^{-1}$ (faixa de deformação C-O-C de éter), 


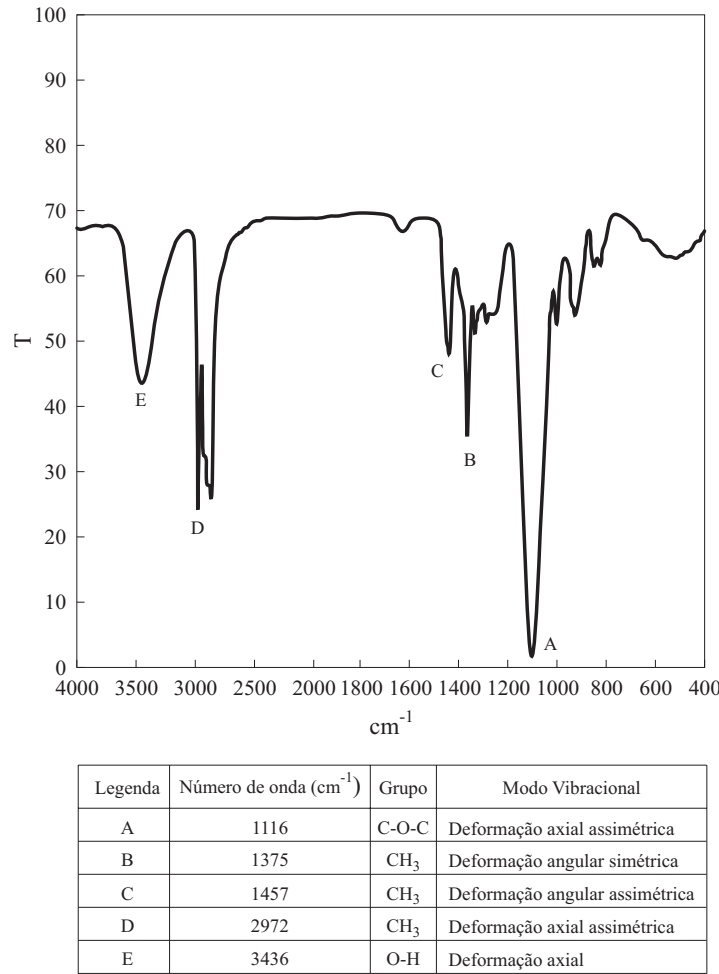

(a)

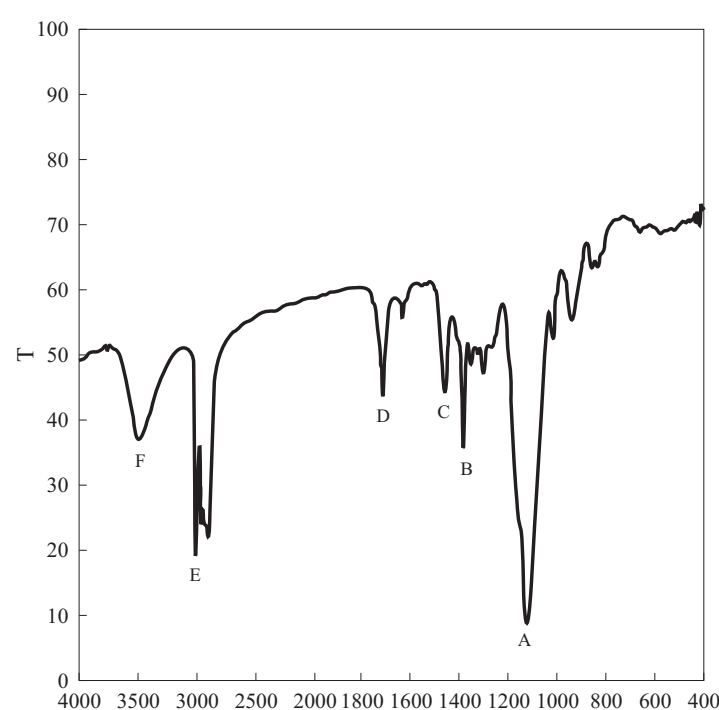

$\mathrm{cm}^{-1}$

\begin{tabular}{|c|c|c|l|}
\hline Legenda & Número de onda $\left(\mathrm{cm}^{-1}\right)$ & Grupo & \multicolumn{1}{|c|}{ Modo Vibracional } \\
\hline A & 1110 & C-O-C & Deformação axial assimétrica \\
\hline B & 1375 & $\mathrm{CH}_{3}$ & Deformação angular simétrica \\
\hline C & 1457 & $\mathrm{CH}_{3}$ & Deformação angular assimétrica \\
\hline D & 1718 & $\mathrm{C}=\mathrm{O}$ & Deformação axial \\
\hline E & 2972 & $\mathrm{CH}_{3}$ & Deformação axial assimétrica \\
\hline F & 3436 & $\mathrm{O}-\mathrm{H}$ & Deformação axial \\
\hline
\end{tabular}

(b)

Figura 2. Espectros de infravermelho de: (a) poli(óxido de propileno); (b) metacrilato de poli(óxido de propileno) podendo sugerir a incorporação do grupo hidrófobo de PPO aos copolímeros sintetizados via técnica de polimerização micelar. Entretanto, em virtude da pequena quantidade de hidrófobo presente no copolímero e da dificuldade de uma quantificação precisa, a técnica de caracterização por infravermelho ofereceu resultados satisfatórios apenas em termos qualitativos.

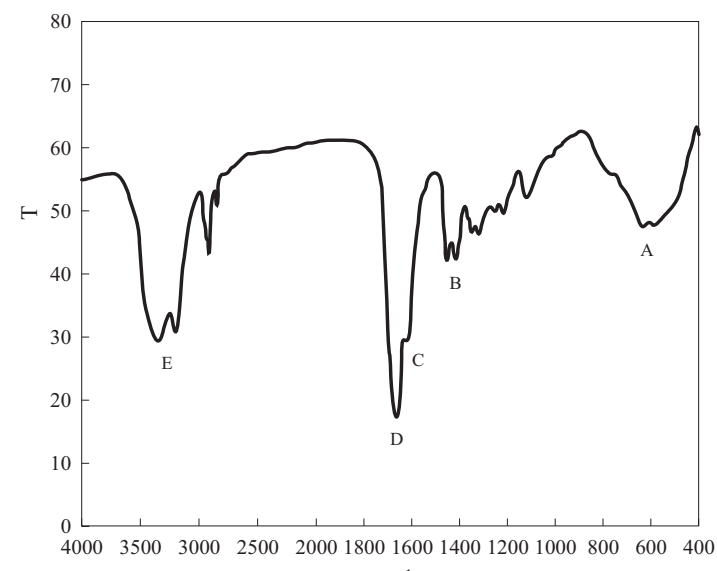

$\mathrm{cm}^{-1}$

\begin{tabular}{|c|c|c|l|}
\hline Legenda & Número de onda $\left(\mathrm{cm}^{-1}\right)$ & Grupo & \multicolumn{1}{|c|}{ Modo Vibracional } \\
\hline A & $800-666$ & N-H & $\begin{array}{l}\text { Deformação angular simétrica } \\
\text { fora do plano }\end{array}$ \\
\hline B & 1414 & C-N & Deformação axial \\
\hline C & 1618 & N-H & Deformação angular \\
\hline D & 1654 & C=O & Deformação axial \\
\hline E & 3340 e 3198 & N-H & Deformação axial \\
\hline
\end{tabular}

(a)

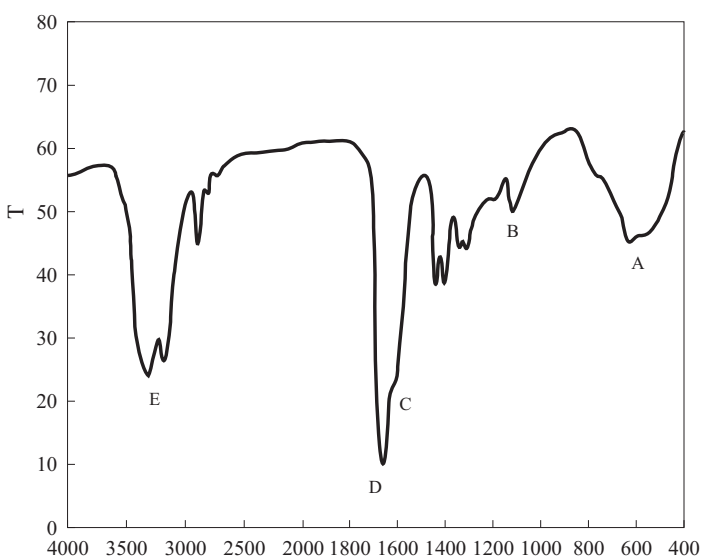

$\mathrm{cm}^{-1}$

\begin{tabular}{|c|c|c|l|}
\hline Legenda & Número de onda $\left(\mathrm{cm}^{-1}\right)$ & Grupo & \multicolumn{1}{|c|}{ Modo Vibracional } \\
\hline A & $800-666$ & N-H & $\begin{array}{l}\text { Deformação angular simétrica } \\
\text { fora do plano }\end{array}$ \\
\hline B & 1122 & C-O-C & Deformação axial assimétrica \\
\hline C & 1618 & N-H & Deformação angular \\
\hline D & 1654 & C=O & Deformação axial \\
\hline E & 3340 e 3197 & N-H & Deformação axial \\
\hline
\end{tabular}

(b)

Figura 3. Espectros de infravermelho de: (a) poliacrilamida; (b) poli(acrilamida-g-óxido de propileno) - amostra 6

Polímeros: Ciência e Tecnologia, vol. 11, no 2, p. 41-50, 2001 
Os copolímeros sintetizados, assim como a poliacrilamida (amostra 4 da Tabela 1) foram analisados quanto às suas propriedades reológicas, conforme ilustrado na Figura 4. Observa-se que estes copolímeros apresentam viscosidade aparente independente da taxa de cisalhamento, sob baixas taxas, e posterior queda da viscosidade sob taxas de cisalhamento mais elevadas, caracterizando um comportamento pseudoplástico, típico de soluções aquosas de polímeros hidrossolúveis, como a poliacrilamida $^{[19]}$. A solução de poliacrilamida, como esperado, apresentou valor de viscosidade mais baixo que as soluções de copolímeros de acrilamida modificados com grupos hidrófobos.

Ainda na Figura 4, são observados comportamentos diferenciados entre os copolímeros analisados. Por exemplo, comparando as amostras 2 e 3, observa-se uma maior viscosidade da última em relação à primeira. Este resultado está de acordo com o esperado, uma vez que a amostra 3 apresenta uma percentagem maior de grupos hidrófobos adicionada na alimentação (ver $\%$ de macromonômero em massa na Tabela 1). No regime de concentração estudado, nesse caso o semidiluído, o aumento de viscosidade é devido às interações intermoleculares entre os grupos hidrófobos. Considerando que o peso molecular da cadeia graftizada é o mesmo (igual a 1000) para ambas as amostras, a que possui maior percentagem em massa de cadeia graftizada apresenta uma maior viscosidade em virtude de uma maior incorporação provável de grupos hidrófobos à cadeia polimérica.

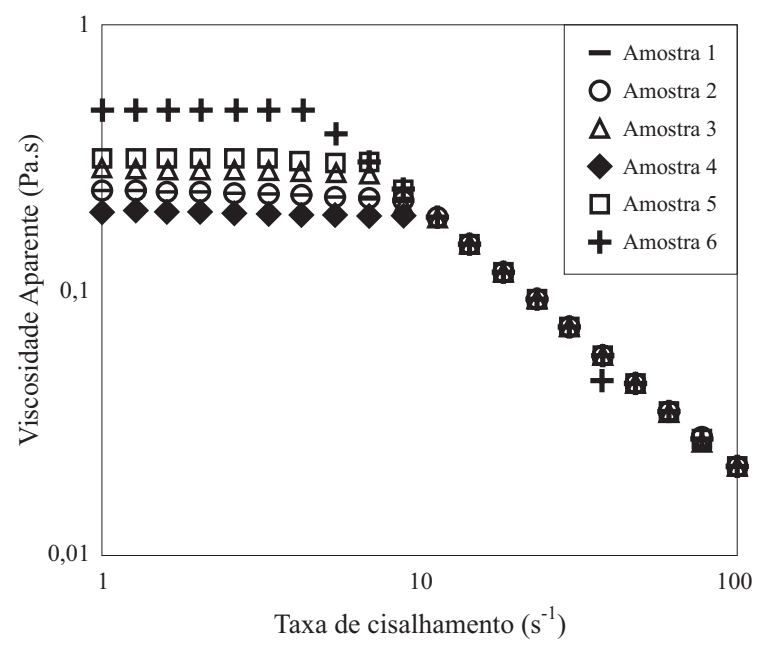

Figura 4. Comportamento viscosimétrico das soluções originais de polimerização micelar das amostras 1 a 6 , obtidas em reômetro Contraves LS-40
Analogamente, quando analisadas as amostras 5 e 6, ambas apresentando peso molecular da cadeia graftizada de PPO igual a 400, a amostra 6 exibe viscosidade mais elevada em relação à amostra 5 , também em função de uma maior percentagem em massa de hidrófobos adicionada na alimentação.

Por outro lado, ao serem analisadas as amostras 3 e 1 , verifica-se que a amostra 3 exibe maior viscosidade em relação à amostra 1 . Estes dois copolímeros apresentam as mesmas percentagens em massa de grupos hidrófobos adicionados na alimentação, porém os pesos moleculares de suas cadeias graftizadas são diferentes: sendo a amostra 1 constituída de PPO 400 e a amostra 2 de PPO 1000. Esse resultado sugere que para uma mesma percentagem em massa de grupos hidrófobos adicionada e diferentes pesos moleculares da cadeia graftizada de PPO, o copolímero que apresenta maior peso molecular da cadeia graftizada, exibe maior viscosidade devido a uma maior facilidade de agregação dos grupos hidrófobos.

As maiores viscosidades das amostras 5 e 6 em relação às demais deve-se, provavelmente, ao fator tempo de reação. O tempo de reação para estas amostras foi de 24 horas, enquanto que para as demais amostras foi de apenas 10 horas. O maior tempo reacional deve ter possibilitado à obtenção de copolímeros com pesos moleculares mais elevados em comparação aos demais ou, ainda, mais elevados graus de incorporação de grupos hidrófobos. Em ambos os casos, o resultado final esperado é de viscosidade mais elevada.

As viscosidades intrínsecas das soluções originais de polimerização das amostras 5 e 6 foram obtidas por meio da extrapolação à concentração zero da relação de Huggins. A solução original da amostra 5 apresentou uma viscosidade intrínseca aproximadamente igual a $2,76 \mathrm{dL} / \mathrm{g}$; enquanto que a solução da amostra 6 (contendo maior teor de hidrófobo que a amostra 5) apresentou uma viscosidade intrínseca aproximadamente igual a $2,58 \mathrm{dL} / \mathrm{g}$. Os resultados estão de acordo com o teor de grupos hidrófobos adicionados na alimentação, uma vez que, no regime diluído, uma maior quantidade de grupos hidrófobos na molécula leva a uma maior contração da mesma, reduzindo a viscosidade intrínseca.

A alteração no comportamento de fluxo de polímeros hidrossolúveis pela introdução de grupos hidrófobos deve-se, basicamente, às associações que ocorrem entre estes grupos em solução. No entanto, 
estas associações podem ser intra- ou intermoleculares de acordo com a concentração na qual se está trabalhando ${ }^{[20]}$. A concentração na qual ocorre a transição de um regime de concentração diluído para um concentrado ou semi-diluído, é chamada de concentração crítica $\left(c^{*}\right)^{[21]}$. É também a partir dessa concentração que as associações entre os grupos hidrófobos deixam de ser intramoleculares e passam a ser do tipo intermoleculares. Conseqüentemente, essas variações quanto ao tipo de interação, que ocorre entre os grupos hidrófobos em regimes diferentes de concentração, tornam-se responsáveis por comportamentos reológicos característicos. Se forem colocadas em gráfico a viscosidade reduzida versus a concentração para polímeros não-associados e associados hidrofobicamente, essa concentração crítica é facilmente observada. Abaixo de c*, a introdução de grupos hidrófobos resulta em um ligeiro decréscimo da viscosidade reduzida, devido às associações intramoleculares, o que leva também a uma queda da viscosidade intrínseca. Acima de c*, verifica-se um aumento da viscosidade da solução do polímero associado, devido às associações intermoleculares entre os grupos hidrófobos ${ }^{[13]}$.

Portanto, quando se deseja trabalhar com valores de viscosidade intrínseca é muito importante ter conhecimento do regime de concentração em questão. Por esse motivo, foram determinadas as concentrações críticas das soluções das amostras 5 e 6 , por meio da interseção de retas obtidas em gráfico de valores de viscosidade específica à taxa de cisalhamento zero $-\eta_{\mathrm{sp}(0)}$ - em função do produto da viscosidade intrínseca da solução pela concentração da mesma $c[\eta]^{[22,23]}$. Para a solução da amostra 5 , a concentração crítica determinada foi de $0,128 \mathrm{~g} / \mathrm{dL}$ e para a solução da amostra $6, c^{*}$ foi igual a $0,115 \mathrm{~g} / \mathrm{dL}$. Com base nesses valores, constatou-se que as viscosidades intrínsecas das soluções foram determinadas em regimes diluídos de concentração, o que garantia apenas a existência de associações intramoleculares entre os grupos hidrófobos ali presentes.

A fim de investigar a reprodutibilidade do método de polimerização micelar, foram determinados os pesos moleculares dos homopolímeros de acrilamida, identificados na Tabela 1 por AM-1, AM-2 e AM-3 e sintetizados sob as mesmas condições reacionais. Para se determinar o peso molecular do homopolímero de acrilamida, foram utilizadas medidas de viscosidade intrínseca e a Equação de Mark-
Houwink-Sakurada, sendo o valor de $K$ igual a $6,5 \mathrm{x}$ $10^{-5} \mathrm{dL} / \mathrm{g}$ e o valor de $a$ igual a 0,82 , para o solvente água, a $30^{\circ} \mathrm{C}^{[24]}$. As três amostras de poliacrilamida apresentaram viscosidades intrínsecas variando entre 4,2 e $4,7 \mathrm{dL} / \mathrm{g}$ e pesos moleculares na faixa de $(7,4-8,5) \times 10^{5}$, respectivamente. Observou-se que o aumento do peso molecular acompanhou uma variação de cerca de $0,5 \mathrm{dL} / \mathrm{g}$ nas viscosidades intrínsecas. Com base neste resultado, foi assumido que variações de viscosidade intrínseca em torno de 0,5 $\mathrm{dL} / \mathrm{g}$ poderiam ser atribuídas a uma variação do peso molecular das amostras.

Assim, em relação às viscosidades intrínsecas, vale notar que as obtidas para os copolímeros de acrilamida contendo grupamentos hidrófobos foram menores que as obtidas para os homopolímeros de acrilamida, essas em torno de 4,5 dL/g. Esse resultado está de acordo com o esperado, uma vez que a presença de grupos hidrófobos incorporados à cadeia do polímero hidrossolúvel leva a interações intramoleculares ${ }^{[25]}$, causando a contração da cadeia polimérica e resultando em uma redução da viscosidade intrínseca do polímero modificado em relação ao não-modificado.

\section{Influência do método de síntese}

Quando comparados os valores de viscosidade intrínseca obtidos para os copolímeros resultantes da técnica de polimerização micelar e aqueles obtidos para os copolímeros resultantes da técnica de polimerização em solução ${ }^{[16]}$, ambos apresentando porcentagens de PPO muito baixas, verifica-se que a técnica micelar gera produtos com viscosidades intrínsecas bem maiores, indicativos de maiores volumes hidrodinâmicos. E, consequentemente, com pesos moleculares bem mais elevados. Este fato pode ser explicado baseando-se no mecanismo de polimerização micelar, que postula que quando um radical em crescimento encontra uma micela contendo monômeros vinílicos polimerizáveis, a concentração de monômero local é bem alta e a orientação é favorecida. Uma polimerização rápida ocorre dentro da micela ${ }^{[26]}$ o que é observada por uma taxa total de polimerização alta gerando polímeros de alto peso molecular ${ }^{[5]}$. Além disso, o uso de mistura de solventes (no caso água e metanol) na técnica em solução gerou produtos com pesos moleculares menores, em função de transferências de cadeia durante a reação. 


\section{Efeito da adição de tensoativos}

A fim de se investigar a influência da adição de diferentes quantidades de tensoativo às soluções em estudo, foram analisados os comportamentos reológicos de soluções dos copolímeros 5 e 6, sob um regime semi-diluído de concentração, contendo diferentes quantidades de SDS. As Figuras 5a e 5b mostram os gráficos de viscosidade reduzida da solução em função da concentração de polímero, na presença de 1 e $3 \%$ de SDS, para as amostras 5 e 6 , respectivamente.

Para ambos os copolímeros, verifica-se que, sob um regime semi-diluído de concentrações, isto é, acima da concentração crítica, o aumento da concentração de tensoativo adicionado à solução levou a um decréscimo da viscosidade reduzida da solução polimérica. Era esperado que a adição de tensoativos a uma solução de polímero (que contém grupos hidrófobos) levasse a uma melhor solubilização deste polímero no meio, devido à melhor interação hidrófobo-solvente gerada pelo tensoativo, aumentado a viscosidade da solução. No entanto, é importante observar sob qual regime de concentra-
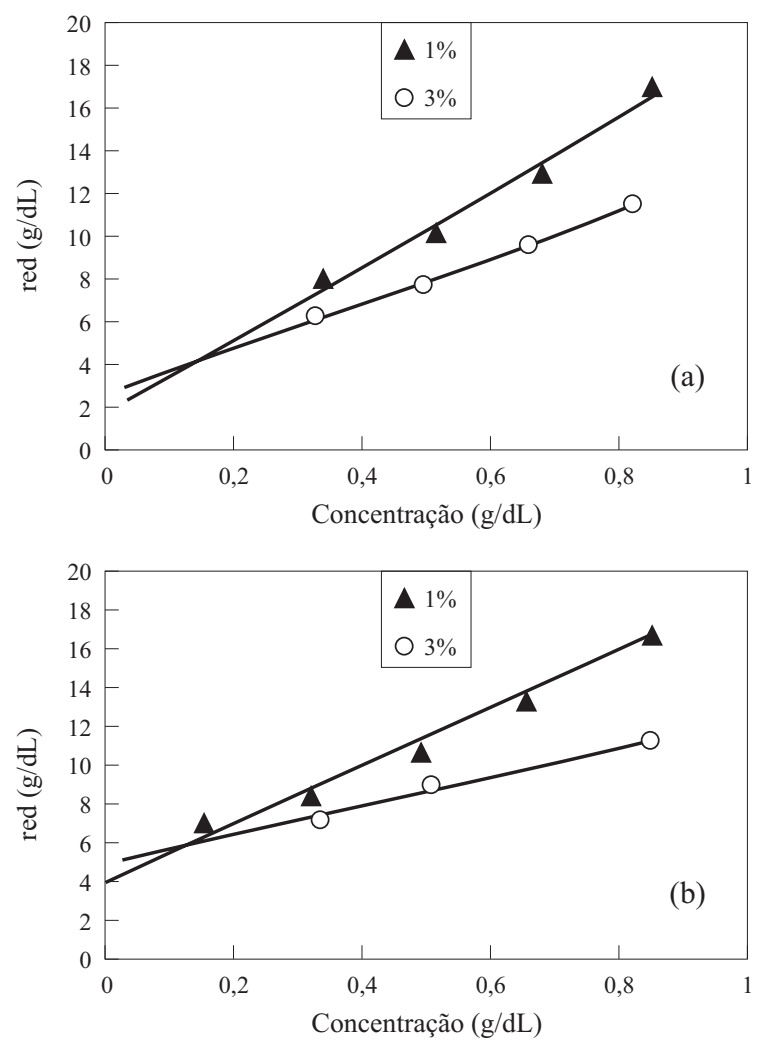

Figura 5. Influência de diferentes quantidades de tensoativos no comportamento reológico das soluções dos copolímeros: (a) amostra 5 da tabela 1; (b) amostra 6 da Tabela 1 ção a solução polimérica encontra-se, pois sob um regime semi-diluído de concentração, as interações entre os grupos hidrófobos presentes no copolímero são de natureza intermolecular ${ }^{[13]}$. Logo, nesse regime de concentração, à medida que se adiciona maior quantidade de tensoativos no meio, este age de forma a melhorar a interação hidrófobo-solvente e o que se observa é uma queda da viscosidade reduzida, causada por uma diminuição das associações intermoleculares, ou seja, uma "quebra" das interações hidrófobo-hidrófobo.

A partir do prolongamento das retas obtidas nos gráficos da Figura 3, verifica-se também que a concentrações mais baixas, isto é, caminhando-se para um regime mais diluído de concentração, a diferença entre as viscosidades reduzidas das soluções, para diferentes quantidades de tensoativo adicionadas, é minimizada; até chegar a uma determinada concentração na qual as retas se cruzam. A partir desta concentração, espera-se um comportamento inverso das viscosidades reduzidas, quando da adição de maiores quantidades de tensoativos. Analogamente, este comportamento inverso pode ser explicado com base no regime de concentração. Isso porque, a concentração na qual as retas se cruzam está associada à concentração crítica da solução e, conseqüentemente, as concentrações abaixo desta caracterizam um regime diluído de concentração.

\section{Influência da adição de sal}

Em várias aplicações industriais, entre elas, a recuperação de petróleo, o meio aquoso utilizado contém eletrólitos, sendo relevante, portanto, o estudo da presença de sais nas soluções aquosas dos polímeros $^{[20]}$.

A influência de sal foi verificada por adição de quantidades determinadas de $\mathrm{NaCl}$ à solução polimérica. Após a adição de sal, foram observadas as alterações de solubilidade das soluções, de forma visual. As massas de sal adicionadas (em gramas), nas quais observava-se turbidez das soluções $(10 \mathrm{~mL})$, foram convertidas para valores percentuais (gramas de sal para $100 \mathrm{~mL}$ de solução). Assim, para a solução original da amostra 5 foram necessários $3,7 \%$ de sal; para a solução da amostra 6, 3,3\% de sal; para a água destilada, mais de $10 \%$ de sal; e para a solução aquosa contendo 3\% de SDS foram necessários 5,2\% de sal.

A partir destes resultados, observa-se que a percentagem de sal necessária para desestabilizar o 
sistema aquoso contendo SDS foi superior às demais percentagens obtidas. Logo, as quantidades de sal adicionadas às soluções poliméricas (amostras 5 e 6) foram responsáveis por uma modificação no sistema da solução polimérica, provavelmente, causando a precipitação do polímero em solução.

É importante observar também que a quantidade de sal, necessária para desestabilizar o sistema da solução polimérica, foi maior na amostra 5 do que na amostra 6. Este resultado está de acordo com o esperado, considerando-se que a amostra 6 deve apresentar maior conteúdo de grupos hidrófobos. Se esses grupos competem com o sal adicionado e/ou se a adição de sal provoca uma mudança no comportamento do polímero em solução, no sentido de minimizar a exposição deste ao solvente, torna-se compreensível que o polímero que apresente maior quantidade destes grupos precipite primeiro, quando adicionada uma mesma quantidade de sal às soluções, ou precipite sob uma menor quantidade de sal adicionada. Com o aumento da concentração de sal ocorre a contração da cadeia polimérica (causada pela agregação dos grupos hidrófobos que se associam intramolecularmente). Esse efeito tem sido observado por outros pesquisadores ${ }^{[2]}$.

\section{Conclusões}

A síntese de poli(acrilamida-g-óxido de propileno) foi realizada com sucesso através da técnica de copolimerização micelar, até então nunca realizada para a preparação específica deste copolímero. Como desejado, os produtos obtidos após a polimerização micelar foram facilmente removidos dos frascos e diluídos, mas os valores de viscosidade alcançados ficaram aquém do necessário para o objetivo de aplicação. Isso se deve ao fato de que a utilização do PPO leva à formação de produtos com menores viscosidades que as encontradas para copolímeros constituídos por grupamentos hidrófobos do tipo cadeias hidrocarbônicas. Ainda assim, a técnica de polimerização micelar gerou polímeros com pesos moleculares bem mais elevados em relação aos apresentados por copolímeros obtidos via técnica em solução.

O maior teor de grupos hidrófobos levou à obtenção de maior viscosidade aparente das soluções em um regime semi-diluído de concentrações, devido às interações intermoleculares.
A pequena concentração de grupos hidrófobos, presentes nos copolímeros sintetizados via técnica de polimerização micelar, dificultou a caracterização por meio de métodos tradicionais como NMR ou análise elementar, em termos quantitativos.

Foi comprovado que o efeito da adição de sal a soluções de copolímeros hidrofobicamente modificados é influenciado pelo conteúdo de grupos hidrófobos presente no copolímero. Sob um regime semi-diluído de concentrações, os sistemas contendo menores quantidades de grupos hidrófobos são mais estáveis à presença de sal no meio.

A adição de tensoativos a uma solução de polímeros que apresentam grupos hidrófobos levou a uma melhor solubilização deste polímero no meio, devido à melhor interação hidrófobo-solvente gerada pelo tensoativo. Sob um regime semi-diluído de concentração, o aumento de concentração de tensoativo causou redução da viscosidade reduzida da solução do copolímero, devido à redução das associações intermoleculares entre os grupos hidrófobos.

\section{Agradecimentos}

Os autores agradecem a CAPES pelo apoio financeiro; ao CENPES/PETROBRAS pela disponibilização de suas instalações para a realização das medidas reológicas; e particularmente a Sônia Cabral de Menezes (Cenpes/Petrobrás) e a Celso Rodrigo de Souza (Cenpes/Petrobrás).

\section{Referências Bibliográficas}

1. Biggs, S., Selb, J. \& Candau, F. - Polymer, 34, p. 580 (1991).

2. Schulz, D. N.; Bock, J.; Valint, P. L. Jr.; Maurer, J.; Turner, S. R.; Duvdevani, I. \& Kowalik, R. M. - Polymer Preprints, 32, p. 86 (1991).

3. Biggs, S.; Hill, A.; Selb, J. \& Candau, F. - J. Phys. Chem., 96, p. 1505 (1992).

4. Yamazaki, A.; Song, J. M.; Winnik, F. M. \& Brash, J. L. - Macromolecules, 31, p.109 (1998).

5. Kramer, M. C.; Welch, C. G.; Steger, J. R. \& McCormick, C. L. - Macromolecules, 28, p. 5248 (1995).

6. Kramer, M. C.; Steger, J. R.; Hu, Y \& McCormick, C. L. - Macromolecules, 29, p.1992 (1996).

7. Branham, K. D.; Davis, D. L.; Middleton, J. C. \& McCormick, C. L. - Polymer, 35, p. 4429 (1994).

Polímeros: Ciência e Tecnologia, vol. 11, no 2, p. 41-50, 2001 
8. Bock, J.; Valint, P. L.; Pacansky, T. J. \& Yang, H. W. H. - U.S. Pat. 5,362,827 (1994).

9. Ul'yanova, N. N.; Tarabukina, E. B.; Sabaneeva, N. V.; Bykova, E. N.; Kallistov, O. V.; Francois, J. \& Klenin, S. I. - Polymer Science, Ser. A, 40, p. 622 (1998).

10. Werner, K.; Komber, H.; Reinhardt, S. \& Steinert, V. Eur. Polym. J., 34, p. 327 (1998).

11. Kramer, M. C.; Steger, J. R.; Hu, Y. \& McCormick, C. L. - Polymer, 37, p. 4539 (1996).

12. Turner, S. R.; Siano, D. B. \& Bock, J. - U.S. Pat. 4,520,182 (1985).

13. Candau, F., Regalado, E. J. \& Selb, J. - Macromolecules, 31, p.5550 (1998)

14. Evani, S. - U.S. Pat. 4,432,881 (1984).

15. Branham, K. D.; Snowden, H. S. \& McCormick, C. L. - Macromolecules, 29, p. 254 (1996).

16. Lucas, E. F.; Silva, C. X. \& Pereira, G. S. - Polymer Bulletin, 39, p. 73 (1997).

17. Sadicoff, B. L. - "Copolimerização micelar de poli(acrilamida-g-óxido de propileno): avaliação reológica e caracterização de suas soluções", Tese de Mestrado, Universidade Federal do Rio de Janeiro, Brasil (1999).

18. Hill, A.; Candau, F. \& Selb, J. - Macromolecules, 26, p. 4521 (1993).
19. Borchardt, J. K. - "Oil-Field Applications", in: Encyclopedia of Polymer Science and Engineering, H. F. Mark, C. G. Overberger, N. M. Bikales and G. Menges (ed.), John Wiley \& Sons, Inc., New York (1987).

20. Yamamoto, H.; Mizusaki, M.; Yoda, K. \& Morishima, Y. - Macromolecules, 31, p. 3588 (1998).

21. Taylor, K. C. \& Nasr-El-Din, H. A. - "Water-soluble hydrophobically associating polymers for improved oil recovery: a literature review" - SPE 29008, p. 675 (1995).

22. Brandão, E. M. - "Caracterização reológica de pectinas de alto grau de metoxilação", Tese de Mestrado, Universidade Federal do Rio de Janeiro, Brasil (1997).

23. Milas, M.; Rinaudo, M.; Knipper, M. \& Schuppiser, J. L. - Macromolecules, 23, p.2506 (1990).

24. Brandrup, J.; Immergut, E. H. - "Polymer Handbook", $3^{\text {a }}$ Ed., John-Wiley, New York, p.VII-8 (1989).

25. Schulz, D. N.; Kaladas, J. J.; Maurer, J. J.; Bock, J.; Pace, S. J. \& Schulz, W. W. - Polymer, 28, p. 2110 (1987).

26. Ito, K.; Tanaka, K; Tanaka, H.; Imai, G; Kawaguchi, S. \& Itsuno, S. - Macromolecules, 24, p. 2348 (1991).

Recebido: 05/07/00

Aprovado 20/04/01 